\title{
An Android Application for Employee Information Security at Master Control Facility
}

\author{
Sanghavi V, Sanjana B Mohan, Shreya M, Swathi Jain, Rajath A N* \\ Department of CSE, GSSSIETW, Mysuru, Karnataka, India
}

DOI: https://doi.org/10.21467/proceedings.1.26

* Corresponding author email: rajathan@gsss.edu.in

\begin{abstract}
In this paper, we have developed a mobile application for storing Master Control Facility (MCF) employee information based on android operating system. All the basic details of the employee can be viewed by any employee of the organization, but the access is limited only to the organization. This application is very helpful to monitor the employees of MCF through mobile phones. The application is implemented using JAVA programming language and result is stored in SQLite database. The developed application should be able to provide an instant access to MCF employee information. Encryption is the basic security measure implemented in this application.

Keywords: Android Operating System; JAVA Programming; Encryption; SQLite Database
\end{abstract}

\section{INTRODUCTION}

Android is a mobile operating system developed by Google, based on a modified version of the Linux kernel and other open source software and designed primarily for touchscreen mobile devices such as smartphones and tablets. A mobile app is a computer program to run on a mobile device such as smartphones and tablets. A mobile app is a computer program designed to run on a mobile device such as a phone/tablet or watch. Mobile applications often stand in contrast to desktop applications which run on desktop computers, and with web applications which run in mobile we browsers rather than directly on the mobile device.

Android software development is the process by which new applications are created for devices running the Android operating system. Officially, apps can be written using Java, C++ or Kotlin using the Android software development kit (SDK). Third party tools, development environments and language support have also continued to evolve and expand since the initial SDK was released in 2008. The Android software development kit (SDK) includes a comprehensive set of development tools. These include a debugger, libraries, a handset emulator based on QEMU, documentation, sample code and tutorials. Currently supported

(C) 2018 Copyright held by the author(s). Published by AIJR Publisher in Proceedings of the $3^{\text {rd }}$ National Conference on Image Processing, Computing, Communication, Networking and Data Analytics (NCICCNDA 2018), April 28, 2018.

This is an open access article under Creative Commons Attribution-NonCommercial 4.0 International (CC BY-NC 4.0) license, which permits any non-commercial use, distribution, adaptation, and reproduction in any medium, as long as the original work is properly cited. ISBN: $978-81-936820-0-5$ 
An Android Application for Employee Information Security at Master Control Facility

development platforms include computers running Linux (any modern desktop Linux distribution), Mac OS X 10.5.8 or later, and Windows 7 or later. Android Studio is the official integrated development environment (IDE) for Google's Android operating system, built on JetBrains' Intellij IDEA software and designed specifically for Android development. It is a replacement for the Eclipse Android Development Tools(ADT) as primary IDE for native Android application development.

This project is based on developing a mobile application that stores the employee information of Master Control Facility with security. In the central government organization, MCF, which is a facility set up by ISRO, the number of employees needed to perform certain functions could run into hundreds. Managing and keeping track of these employees could prove bulky and cumbersome. The need for mobile app for storing MCF employee information assists in monitoring of employee's records. Searching for a particular employee record could take hours to find which is not productive in today's fast paced and technologically driven organization. This is a simple scenario which can store all the information related to a particular employee. The application to be developed should save the contact details of MCF employees, email-ID along with their images. It should be login based and should logout automatically after a specified period. Provision to change the password should be provided. The application should not be allowed to be installed in any mobile other than authorized one. Updating of data should happen through file-based mode and the file should be in encrypted format for official contact number with verification process. The application should store contact details of other centre and should be displayed on request and the provision to copy the displayed name and contact number. It should give a search option for employee code, and partial name for all contacts. There are security measures that are implemented in this application, preventing unauthorized users accessing the details of the employees. Some of the security measures implemented are encryption, progaurd security, screen shot disable feature, nonsharable of the application feature and many more.

\section{LITERATURE SURVEY}

[1] 'An Android based Employee Tracking System' “In this paper, an employee tracking system based on Android operating system was developed. All the activities of the employee will be monitored using this system which includes scheduling information and time off requests are often considered part of personal tracking; as this information will enable managers know when employees are expected to actually be in the office or other work areas." [2] 'Employee Management Application within an Organization using Android Smartphones' "Employee management application is a powerful tool to relieve the user from the complicated task of handling employee scheduling manually. This application using android smart phone's is trying to build an android application for log the data on the server automatically. It is helpful for the managers to monitor their employee through mobile phones. This application is use to maintain transparency between managing team and employee." [3] 
'Employee Tracking and Monitoring System using Android' “In this paper, we discuss about the design and implementing admin, employee application and Centralized server for monitoring employees of the company using android by separating corporate and personal data. In this paper we provide different security profile on same smartphone. In this system we are using dynamic database utility which retrieves data or information from centralized database." [4] 'Employee Monitoring System using Android Smart Phone' "In this paper, we discuss about the design and implementing admin application, employee application and Centralized server for monitored company employee's using android technology. In this system we are providing dynamic database utility which retrieves data or information from centralized database." [5] Employee Surveillance System using Android Smartphone "This system is actually the integration of Employee Monitoring and GPS location Tracking System using Android phone. All the activities of the Employee will be monitored using this system. The system work s on $3 \mathrm{G}$ communication between the terminal ends. All the activities of an employee on his cell phone and computer, like data usage, all incoming and outgoing calls, web browsing and secured document modification and illegal transfer of company's informative details like blue print, stocks, projects etc. will be set under surveillance."

\section{EXISTING SYSTEM}

The earlier system involved a great deal of manual work. The problem definition for designing the system is to maintain data of employee, to make easy controlling employees, to use technology for accurate and timely processing by fully privacy and full authority access. The objective of the project is to set up employee information storing system to store all details of the employee. To eliminate or reduce as much as possible the hardships of existing system and avoid errors while entering data. It's a manual process not a user-friendly because of storing the data is very slow and not maintained efficiently. It is manual control of storing and accessing the employee information without any security. This can be replaced by using proposed system.

Disadvantages of Existing System:

- Needs for extra manual effort.

- In existing system, it is a standalone process. Normal people cannot track their employee status.

- Less accuracy.

- Danger of losing some files.

- Certain required report is not available.

- Time consuming process.

Proceedings of the $3^{\text {rd }}$ National Conference on Image Processing, Computing, Communication, Networking and Data Analytics (NCICCNDA 2018) 
An Android Application for Employee Information Security at Master Control Facility

\section{PROPOSED SYSTEM}

This project is connected with the mobile application for storing Master Control Facility employee information based on android operating system. This application is very useful to monitor the employees of MCF through mobile phones. This application is implemented using JAVA programming language and result is stored in SQLite database. The data is accessed within the intranet. This application maintains a database which has the details of the employees such as their name, unique id, image, designation, date of joining etc. this application must be placed in the head office of any organization. This android application cannot be transferred from one device to another device and only the organization employees with the authorized mobile phones are allowed to access the information.

Advantages of proposed system:

- Help in maintaining the computerised employee details.

- More efficient and reliable.

- Less time consuming and easy to use.

- Avoid human error and effort for maintaining daily data.

- Huge data storage with less computer memory.

\section{DATA FLOW DIAGRAM}

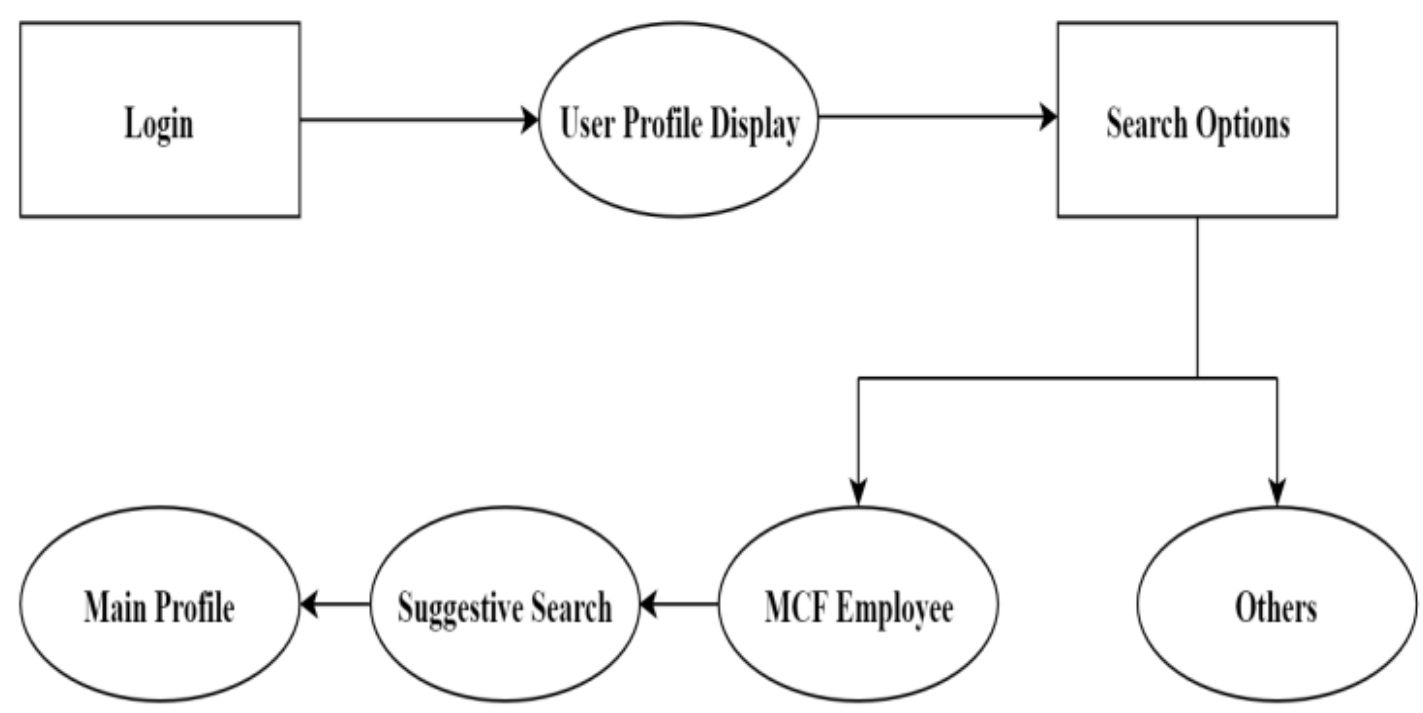




\section{REFERENCES}

[1] Etuk Enefiok A, Onwuachu Uzochukwu C. (November, 2016), An Android based Employee Tracking System, International Journal of Computer Applications (0975-8887).

[2] Sweeti M Shambharkar, Neha S Mankar, Sneha A Jikar, Prof.Priti P Dafale, Employee Management Application within an Organization using Android Smartphones, International Journal of Research in Science \& Engineering, Volume: 1 Issue: 2.

[3] Sonal Kasliwal, Sushma Kotkar, H D Gadade, Employee Tracking and Monitoring System using Android, International Journal of Innovative Research in Advanced Engineering(IJRAE), ISSN: 2349-2763, Issue 03, Volume 3 (March 2016).

[4] Kalyani Bhagwat, Priyanka Salunkhe, Employee Monitoring System Using Android Smart Phone, International Journal on Recent and Innovation Trends in Computing and Communication, ISSN: 2321-8169, Volume:3 Issue:2.

[5] Rachana Sabale, PranjalPawar, Employee Monitoring System Using Android Smartphone, International Journal of Computer Science and Information Technologies, ISSN:0975-9646.

[6] M D Nirmal, Rohit Koul, Employee Surveillance System using Android Smartphone, International Journal of Innovative Research in Advanced Engineering, IJARIIE-ISSN(O)-2395-4396.

Proceedings of the $3^{\text {rd }}$ National Conference on Image Processing, Computing, Communication, Networking and Data Analytics (NCICCNDA 2018) 